\title{
Analyzing the Factors that Effect Maximum Time to Repair Thermal Energy Systems in Cold/Arctic Climates
}

\author{
Bjorn Oberg ${ }^{1 *}$; Angela Urban (1); Emmett Leffel (2); Jonathan Goebel (1); Matthew Perry (3); Dragos Vas (4); Dayne \\ Broderson (3); Richard Liesen (1) and Alexander Zhivov (1) \\ 1: USACE ERDC CERL, United States of America \\ 2: Alaska Thermal Imaging LLC \\ 3: University of Alaska Fairbanks \\ 4: USACE ERDC CRREL, United States of America
}

\begin{abstract}
Resilient energy systems are those that can prepare for and adapt to changing conditions, and recover rapidly from disruptions including deliberate attacks, accidents, and naturally occurring threats. This makes thermal energy systems resilience especially important in extreme climates such as arctic or tropical environments. While metrics and requirements for availability, reliability, and quality of power systems have been established (DoD 2020), similar metrics and requirements for thermal energy systems are not well understood. In one of the first attempts to address this deficiency, a study was conducted to better understand the factors that affect maximum time to repair thermal energy systems. Maximum time to repair of thermal systems can be defined in terms of how long the process can be maintained or the building remains habitable or protected against damage from freezing of water pipes, sewer, fire suppression system, protect sensitive content, or start growing mold during extended loss of energy supply with extreme weather events. The purpose of this paper is to present the methodology and results of a novel temperature decay test conducted during the winter, along with blower door tests on five representative military buildings in Alaska. The results from the field tests described in this paper show that the distribution of temperature decay is not uniform throughout the building and that it will vary depending on solar position, building features and wind direction. This demonstrates that strategic placement of personnel, equipment and facilities that are critical to building operations, can extend operation time during a thermal energy disruption.
\end{abstract}

\section{BACKGROUND}

Resilient military communities have been determined to be an emerging need by the United States Department of Defense (DoD). A building is said to be resilient if it is able to maintain contiuity of operation in regard to occupant safety, health and comfort over an extended period of time without significant damage to the building and its sustems (ASHRAE 2015). While resilience covers a broad area of expertise, this paper will specifically focus on therml energy systems resilience, which is esepecially important for extreme climates, such as arctic or tropical environments. While metrics and requirements for availability, reliability, and quality of power systems have been established (DoD 2020), similar metrics and requirements for thermal energy systems are still not well understood. Thermal/environmental equirements for normal (blue skies) and emergency (black skies) operations are described in detail in (Zhivov et al. 2021a). If these requirements are not met, the building may not be able to support mission-critical processes, habitibility requirements for mission essential workers, as well as becoming suceptible to mold, mildew, and basic building faliures. Thermal comfort conditions in a mission-critical facility during normal operations differ from cold stress threshold limits above which mission operators are able to conduct mission-critical tasks. This results in a difference between the total heat load during normal operations and a critical heat load during emergency operations.

Military installations are similar to many building types found in cities all over the country in that they comprise a condensed version of commercial, residential, and industrial building types. Military installations typically contain such common building types as office buildings, child development centers, multifamily/dormitory housing, laboratories, and storage warehouses. While the design of individual buildings may vary based on function type, a number of other factors remain relatively constant, including, but not limited to, accessibility, aesthetics, cost-effectiveness, operations, preservation, productive environment, safety

\footnotetext{
*Bjorn Oberg: bjorn.k.oberg@usace.army.mil
} 
and security, and environmental sustainability (WBDG 2020).

Resilient energy systems are those that can prepare for, and adapt to, changing conditions, and recover rapidly from disruptions including deliberate attacks, accidents, and naturally occurring threats (PPD-21, U.S. Army 2015). A quantitative approach to resilience of a system supplying energy to the building is presented by Zhivov et al (2021a) and may include (but is not limited to) the following metrics (Zhivov 2021a):

- Energy System Robustness

- Energy System Recovery

- Energy Availability

- Energy Quality.

The first three parameters are critical for selection of the energy supply system architecture and technologies that comprise it to satisfy requirements related to energy system resilience. Energy System Robustness is a metric showing power availability, $\mathrm{P}$ (in $\mathrm{kW}$ and/or $\mathrm{kBtu} / \mathrm{hr}$ ) to satisfy critical mission loads over a period of time immediately following a disruptive event, measured as a fraction of the mission-critical requirement or a fraction of the Baseline energy requirement. Energy System Robustness is defined as "the ability to absorb shocks and continue operating" (NERC). Using the Energy System Robustness metric, we can quantify the overall resilience of a system in two phases: absorption of the event, and recovery. Error! Reference source not found. illustrates a systems performance in response to a disturbance, which occurs without warning, such as with seismic events. Immediately following the event, there is a sharp drop in mission availability. The change in mission availability from the baseline to the degraded state represents the robustness of the system to that particular event. The smaller the change in mission availability, the more robust the system. The time required to restore the system to its baseline state is referred to as Energy System Recovery.

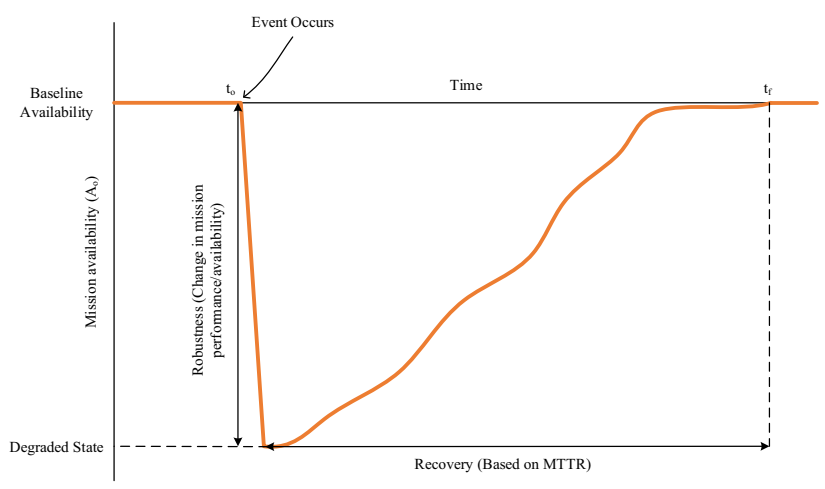

Figure 1. System Response to a Disruptive Event.

Depending on mission needs, it may be more important to prioritize either robustness or recovery. Energy system robustness may be beneficial for improving overall resilience at remote sites where recovery time is limited by the difficulty of getting replacement parts to the site. In other cases, it may be more important to prioritize recovery from an event as opposed to robustness. Energy Availability is defined as the percentage of time that an energy system is available to perform its required function(s). Energy Quality is another important quantitative metric for the energy system serving critical functions and should be considered as a design parameter for internal building energy systems. However, the Energy Quality concept is more important to consider for electrical systems than for thermal energy systems. Following a contingency event, the facility or site should have a plan in place to adapt to the issue and recover quickly from its affects. Due to limitations of personnel, resources, and logistics, repairs for all components may not occur simultaneously. Some assets also may be required to be restored in sequence. The priority shall be given to restoring energy to the level satisfying needs of missioncritical loads. In this case, the Mean Time To Repair (MTTR) of the system providing mission-critical load shall be smaller than maximum allowable downtime assigned based on the configuration of the internal energy system and a storage capacity for heat and power.

\section{MAXIMUM ALLOWABLE DOWNTIME}

The maximum allowable downtime for thermal systems can be defined as follows. In the event of a thermal energy disruption, how long (1) the buildings mission can be maintained, (2) will the building remain habitable, (3) will the building be protected against damage from freezing water pipes, sewer pipes, or fire suppression systems, (4) can sensitive facilities or equipment be sustained, or (5) mold groth is initiated. A thermal resilience design guide (Kesik 2019) defines the threshold for building habitability during heating season as $60^{\circ} \mathrm{F}\left(16^{\circ} \mathrm{C}\right)$ and for cooling season as $86^{\circ} \mathrm{F}\left(30^{\circ} \mathrm{C}\right)$. Mission operators may select different thresholds based on age, health, or level of training of inhabitants.

The major factors affecting the maximum allowable downtime or the time when the internal building temperature reaches the habitability and sustainment thresholds are:

- Difference between inside and outside air temperatures.

- Building envelope leakage rate.

- Building envelope insulation properties, including insulation levels of its components, and thermal bridging.

- Internal thermal loads (people and appliances/equipment connected to electric power).

- Thermal mass of the building

The thermal mass of the building structure is determined by the materials used in the construction of the building and refer to those composed of concrete, masonry or stone materials that enable the building to absorb and store heat to provide "inertia" against temperature fluctuation. Alternatively buildings that are 
wood or metal framed, typically have a low thermal inertia.

Figure 2 shows how these factors will influence building habitability and sustainment.

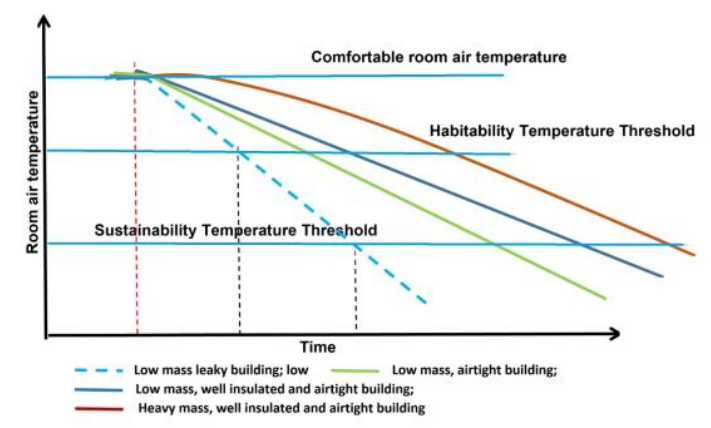

Figure 2. Notional Example of Temperature Decay Rate for Different Types of Building Envelopes.

During emergency situations, maintaining optimal comfort conditions may not be feasible. In this case, mission-critical areas can be conditioned to different thresholds of thermal energy requirements. These requirements include the ability to perform the required work in a safe and efficient manner, provide support for the processes housed in the building, and ensure the long-term sustainability of the building. In the event of a thermal energy disruption, air temperatures in spaces with mission-critical operations must be maintained above $60.8^{\circ} \mathrm{F}\left(16^{\circ} \mathrm{C}\right)$ (Zhivov et al. 2021b).

\section{OBJECTIVES AND SCOPE}

The purpose of this paper is to present the methodology and results of a simulated thermal energy disruption, in order to understand better what factors contribute to a buildng's thermal decay during an emergency scenario. These data will help provide facility managers with an estimated maximum allowable downtime for their building based on external weather conditions, building characteristics, and other factors. In order to ensure continuity of operations it is important to understand how much time is available to fix the problem before the indoor air temperature reaches habitability or sustainability thresholds (Zhivov et al 2021a) and to identify areas in the building that are the most vulnerable to disruption of heat. Tests were conducted in five buildings located at Fort Wainwright (FWA) and Fort Greely (FGA) in January 2020 with the outdoor air temperature ranging between $-20^{\circ} \mathrm{F}$ and $40^{\circ} \mathrm{F}\left(-29^{\circ} \mathrm{C}\right.$ and $\left.-40{ }^{\circ} \mathrm{C}\right)$. Air permeability of a building is a significant factor affecting loss of heat by the building. To obtain this information for the five selected buildings, blower door tests were conducted in July 2020. Prior to these tests, building characteristics information were collected from available drawings, specifications, retrofits, and building walk throughs.

\section{METHODOLOGY}

To establish guidelines for maximum time to repair thermal systems before habitability or sustainability thresholds are reached, it is important to understand the external factors that contribute to a buildings thermal decay, to what extent these factors play a role, and the distribution of indoor air temperature throughout the building during a thermal energy disruption. In one of the first attempts to better understand these factors, a novel thermal decay test (TDT) was developed to simulate a thermal energy disruption to a military installation. The thermal decay test involved instrumenting the building with temperature sensors, removing the heat sources to the building, and recording air and surface temperatures in throughout the building over an extended period of time. To establish some level of consistency and to streamline the process, a test protocol was established.

Indoor temperatures were recorded using surface and ambient temperature sensors placed in key locations throughout the buildings. Sensor locations were chosen to capture data in critical areas (e.g. mechanical rooms with exposed waterlines), and data for areas that susceptible to the effects of wind. Additionally, sensors were placed near exterior doorways to better understand the effects of researchers opening doors while monitoring the buildings. For the surface temperatures, UX120-006M HOBO data loggers with four TMC20HG temperature probes (Accuracy: $\pm 0.27^{\circ} \mathrm{F}$ $\left.\left[ \pm 0.15^{\circ} \mathrm{C}\right]\right)$ were used. These sensors were placed in corners of the buildings to analyze temperature differences in windows, walls, ceilings, and floors. The surface temperature on internal and external walls were measured and analyzed with a special attention paid to the difference between internal versus external walls, wall orientation, and walls below or above grade. For the interior ambient temperatures, UX100-003 HOBO data loggers (Accuracy - Temp: $\pm 0.38^{\circ} \mathrm{F}\left( \pm 0.21^{\circ} \mathrm{C}\right)$; $\mathrm{RH}: \pm 2.5 \%$ ) were used and were typically suspended from ceilings in the center of rooms. These sensors also captured relative humidity which did not show any significant changeover the course of the tests. External temperature, wind speed, and wind direction were recorded using a local base meteorological (MET) station. Internal loads were estimated by using typical electrical load and occupancy data. Building insulation properties were estimated by using building design documents, by samples obtained from exterior walls, and from on-site inspections. Information about the protocol and results of the air barrier tests can be found in (Leffel 2021).

\section{Selection of buildings for tests}

Prior to this work, in 2019, thirty buildings were subjected to building airtightness tests at Fort Wainwright and Fort Greely, five of which were selected for the thermal decay study. Due to the risks and invasiveness associated with the thermal decay tests, not all of the 30 buildings were available for this 
study. Of the five buildings selected, each varied by building type and building characteristics. They were selected primarily based on availability, era of construction, and building design. The era of construction was of particular importance, because throughout the years different construction materials were preferred. Generally speaking, older buildings used heavier materials (CMU's, stone, etc) and newer buildings used wood and metal framing. Additionally, different building design charateristics may prove to be more thermally resilient than others. This allowed a comparison of different building designs and different materials capacity for retaining thermal energy. At Fort Wainwright, two office buildings and a laboratory were selected. At Fort Greely, an office and a multi-use facility were chosen.

\section{Fort Wainwright}

Building A, a Battalion Headquarters (office building) was constructed in 2015 . This predominately military-utilized office includes administrative areas, classrooms, and special function space. In buildings like this it is not uncommon to find small gyms, weapons storage rooms, and dining areas located within. This particular building received Silver Certification for Leadership in Energy and Environmental Design (LEED) and consists of metal wall panels and a metal roof. When the airtightness test was conducted at the facility, it initially failed to meet the minimum U.S. Army Corps (USACE) requirements. This air leakage rate is 0.208 CFM75/sq $\mathrm{ft}\left(0.033 \mathrm{~m}^{3} / \mathrm{h} / \mathrm{m}^{2}\right)$ and has a EqLA75 of 5.7 sq $\mathrm{ft}\left(0.529 \mathrm{~m}^{2}\right)$ and occurred primarily at the roof to wall barrier joint. Upon correction and sealing, a 26\% reduction was achieved (Leffel 2021). The walls and roof were estimated to have a R5.28 and R10.57 (SI) insulation rating respectively.

Building B, a small open-floor design building (office building) that includes an unconditioned storage area, was built in 1999 and consists of a wooden frame with metal siding. This building was originally constructed to serve as a small warehouse for a recycling facility. When it was repurposed and renovated in 2010 , floors and ceiling panels were installed having radiant heat. During the airtightness test, the leakage rate was $0.095 \mathrm{CFM}_{75} / \mathrm{sq} \mathrm{ft}\left(0.015 \mathrm{~m}^{3} / \mathrm{h} / \mathrm{m}^{2}\right)$ with a EqLA 75 of 0.5 sq ft. $\left(0.046 \mathrm{~m}^{2}\right)$ Leakage primarily occurred through the interior gypsum sheathing, window and door sills, and the common wall between the main conditioned room and the unconditioned storage room. This building was found to be overheating due to the heating systems and the poorly ventilated mechanical room. The walls and the roof were estimated to have a R4.58 and R5.28 insulation rating respectively.

Building C, a laboratory facility, was constructed in the 1950s but has undergone complete renovation in recent years. It consists of office and meeting space as well as medical laboratories. The facility has two floors and a basement. The construction consists of concrete walls with an exterior surface of Expanded Polystyrene
(EPS). An airtightness test was not administered on this building in the previous study. The walls and the roof were estimated to have a R30 and R20 insulation rating respectively.

\section{Fort Greely}

Building D, a multipurpose warehouse and office building, has two separate zones and is divided by a concrete masonry unit (CMU) wall. The facility was constructed in 1955, and includes more recent (2012) upgrades such as exterior insulation and finish system (EIFS) to the exterior walls, roofing improvements, overhead door and window replacements, and improvements to the ventilation system. On one side of the CMU wall, there is a wood shop with a two-story office space. On the other side is a garage bay. The airtightness test found an air leakage rate of 0.155 $\mathrm{CFM}_{75} / \mathrm{sq} \mathrm{ft}\left(0.025 \mathrm{~m}^{3} / \mathrm{h} / \mathrm{m}^{2}\right)$ and an EqLA 75 of $3.3 \mathrm{sq} \mathrm{ft}$ $\left(0.307 \mathrm{~m}^{2}\right)$ and showed that there is significant amount of leakage through (1) the roof to wall joint in the garage bay, (2) multiple windows and doors, and (3) $2^{\text {nd }}$ floor roof to wall joint on the south side. The walls and the roof were estimated to have a R2.64 and R4.93 insulation rating respectively.

Building E, a multi-use facility, contains three separate isolated zones: a theater, classrooms, and an indoor recreational area. Built in the 1950s, the construction consists of concrete with a steel roof and metal studs. The building envelope was upgraded in 2012 , but when the airtightness test was administered, leakage was found through wall to roof joints at the steel roof, HVAC penetrations, and doors. The airtightness test found a leakage rate if $0.146 \mathrm{CFM}_{75} / \mathrm{sq} \mathrm{ft}(0.023$ $\left.\mathrm{m}^{3} / \mathrm{h} / \mathrm{m}^{2}\right)$ and an EqLA 75 of $2.8 \mathrm{sq} \mathrm{ft} .\left(0.260 \mathrm{~m}^{2}\right)$ The walls and the roof were estimated to have a R2.64 and R3.87 insulation rating, respectively.

\section{Constraints}

Selection of these buildings was based on the era of their construction, and on their availability. To ensure that the buildings incurred no substantial damage, it was decided that the thermal decay study was halted when the internal ambient air temperatures reached $45^{\circ} \mathrm{F}$ $\left(7^{\circ} \mathrm{C}\right)$. Allowing for a buffer point prior to entering the threshold of freezing temperatures was necessary to allow maintenance staff adequate time to restore heat to the buildings. This ensured continuity of operations without any permanent disruption to the thermal systems. Additionally, it was important to identify prior to the start of the study any vulnerable areas of the building, such as mechanical rooms, exposed water pipes, and poorly insulated areas such as arctic entries. FWA and FGA Directorate of Public Works (DPW) staff were on call for the duration of the tests in case the temperature threshold was met before the anticipated time.

Buildings were monitored approximately once every 2 hours during the test to ensure damage was not 
being done to the buildings. Since the two locations are 100 miles from one another, it was necessary to conduct the study on separate dates, however, the buildings on each installation were tested concurrently. Additionally the tests were conducted when the buildings were unoccupied, or with as few personnel as possible, to minimize potential sources of error. This was a coordinated effort with the DPW at both locations, who were critical to making installation personnel aware of the importance of the study and for obtaining permission to contact maintenance staff in case of an emergency, as well as other risk management measures that were not initially considered by the research team. Additionally, it was important to engage with the DPW as they are key stakeholders for this study.

\section{TEST RESULTS}

The thermal decay tests at Fort Wainwright Alaska (FWA) and Fort Greely Alaska (FGA) were conducted over the course of several months from January through February. Data were logged using timestamps in Alaska Standard Time (AKST), Table 1 lists the results of the TDTs at Fort Wainwright, Alaska and Fort Greely, Alaska.

Table 1. Thermal Decay Test Timeline and Environmental Conditions.

\begin{tabular}{|c|c|c|c|c|}
\hline Building & $\begin{array}{c}\text { Date } \\
\text { Tested }\end{array}$ & $\begin{array}{c}\text { Test } \\
\text { Duration }\end{array}$ & $\begin{array}{c}\text { Outdoor } \\
\text { Temperature }\end{array}$ & $\begin{array}{c}\text { Wind } \\
\text { Speed } \\
\text { and } \\
\text { Direction }\end{array}$ \\
\hline $\mathrm{C}$ & $\begin{array}{c}\text { Jan } 09 \\
2020\end{array}$ & 8 hours & $\begin{array}{c}-40^{\circ} \mathrm{F}(- \\
\left.40^{\circ} \mathrm{C}\right)\end{array}$ & $0 \mathrm{mph}$ \\
\hline A & $\begin{array}{c}\text { Jan } 17 \\
2020\end{array}$ & 8 hours & $\begin{array}{c}-20^{\circ} \mathrm{F}(- \\
\left.29^{\circ} \mathrm{C}\right)\end{array}$ & $0 \mathrm{mph}$ \\
\hline $\mathrm{E}$ & $\begin{array}{c}\text { Jan } 18 \\
2020 \\
\end{array}$ & 17 hours & $-9^{\circ} \mathrm{F}\left(-23^{\circ} \mathrm{C}\right)$ & $\begin{array}{l}62 \mathrm{mph} \\
\text { Gusts East }\end{array}$ \\
\hline $\mathrm{D}$ & $\begin{array}{c}\text { Jan } 18 \\
2020\end{array}$ & 17 hours & $-9^{\circ} \mathrm{F}\left(-23^{\circ} \mathrm{C}\right)$ & $\begin{array}{l}62 \mathrm{mph} \\
\text { Gusts East }\end{array}$ \\
\hline B & $\begin{array}{c}\text { Feb } 26 \\
2020\end{array}$ & 29 hours & $\begin{array}{c}-20^{\circ} \mathrm{F}(- \\
\left.29^{\circ} \mathrm{C}\right)\end{array}$ & $0 \mathrm{mph}$ \\
\hline
\end{tabular}

The temperatures at FWA ranged from $-20^{\circ} \mathrm{F}$ to $40^{\circ} \mathrm{F}\left(-29^{\circ} \mathrm{C}\right.$ to $\left.-40^{\circ} \mathrm{C}\right)$ with virtually no wind $(0 \mathrm{mph})$. The temperatures at FGA stood at $-9{ }^{\circ} \mathrm{F}\left(-23^{\circ} \mathrm{C}\right)$, but there were substantial wind speeds (up to $62 \mathrm{mph}$ (100 kph)). The tests on Bldgs. D and E at FGA started at approximately 3 p.m. on 17 January 2020 and ended at approximately 8:30 a.m. on 18 January 2020. Bldg. C at FWA was tested on 09 January 2020 starting at 8:30 a.m. and ending at 4:30 p.m. The outdoor temperatures were $-40^{\circ} \mathrm{F}\left(-40^{\circ} \mathrm{C}\right)$ and rose to $-37^{\circ} \mathrm{F}(-$ $38^{\circ} \mathrm{C}$ ) throughout the course of the test. Bldg. A at FWA was tested on 17 January 2020 from 8:00 a.m. to 4:00 p.m. with temperatures reaching $-20^{\circ} \mathrm{F}\left(-29^{\circ} \mathrm{C}\right)$. Bldg. B at FWA was tested from 8:00 a.m. on 26 February 2020 to 1:00 p.m. on 27 February 2020, during which temperatures ranged from $-20^{\circ} \mathrm{F}$ to $40^{\circ} \mathrm{F}\left(-29^{\circ} \mathrm{C}\right.$ to $-40{ }^{\circ} \mathrm{C}$ )

\section{FWA BIdg. A - BNHQ}

Bldg. A showed no significant change in internal building temperature over the course of the test. There are a number of reasons why this might be the case. For one, due to external contraints, this building was only able to be studied for 8 hours as opposed to the longer test studies at 17 and 29 hours respectively. However, other buildings showed a significant temperature decay after 8 hours. This can be attributed to its higher insulation values in the walls and the roof as well as its large thermal mass. This test was conducted throughout the day so the building would have experienced heat gains from solar radiation. Additionally, it should be highlighted that this building achieved LEED Silver in certification. In comparison, the other buildings included in this study had no LEED certification and were not held to the same energy efficiency standards. The LEED designation contributes to the reduction in energy demands, and it addresses envelope requirements, such as overheating, ventilation, thermal conductivity, exposed surfaces, temperature differential, airtightness, and façade orientation. With the latter requirement, façade orientation is an important consideration for construction in cold climates, as the direction of the openings and the window area proportion must be oriented in a manner that considers solar radiation and control.

\section{FWA Bldg. B - Storage Warehouse}

The test at Bldg. B started at approximately 8:00 a.m. on 26 February 2020. The test ran throughout the course of the day while the building was occupied by several DPW employees. Figure $4 \mathrm{a}$ shows the ambient temperatures from several rooms distributed throughout the building. The test showed a relatively uniform temperature decay throughout the building, with a slight exception to the south restroom which stayed a few degrees cooler than the other rooms throughout the test. This is likely due to the north restroom door being propped open, allowing heat to flow freely from the plans room to the restroom leading these rooms to follow a similar pattern.

The building continued to increase in temperature several hours into the test until about 10:00 a.m. on $26 \mathrm{Feb}$ for the south restroom and 4:00 p.m. on $26 \mathrm{Feb}$ for the north restroom and the plans room. There are several explanations for this. One is that this building has a glycol heating system that continued to pump glycol throughout the building during the test. The residual heat stored in the glycol provided some amount of heat to the building until that heat eventually came to an equilibrium with the rest of the building. In addition, heating from solar radiation played a role. The plans room had several windows that allowed sunlight to enter at sunrise from the east (8:00 a.m.) and that room was connected to a conference room, via an open door, with windows allowing sunlight to enter during the sunset from the west (6:00 p.m.). 
The surface temperatures on the eastern and western windows spiked throughout the day as they were exposed to direct sunlight as shown in Figure b. This increase in surface temperature corresponds to increases in ambient temperature. This occurred throughout the test even when the primary heat source had been removed. Heat gained from solar radiation and residual heat in the glycol heating system provided this building with extended operation time with most rooms not exceeding the habitable threshold.

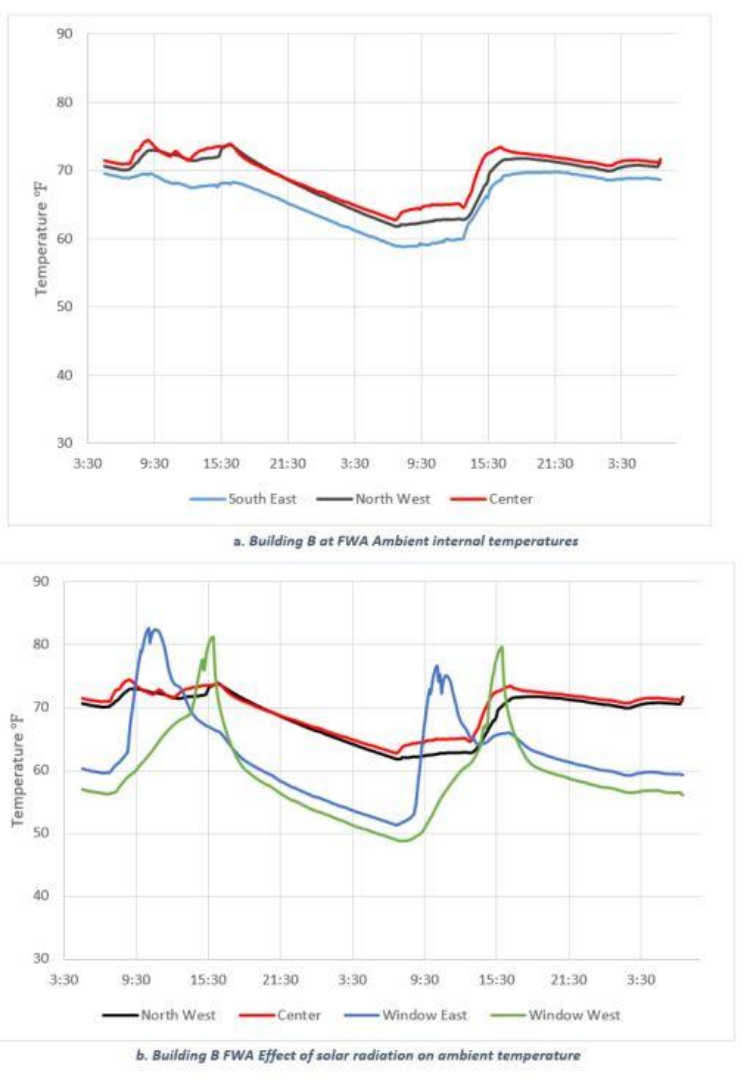

Figure 4. Test Results from Bldg. B.

\section{FWA BIdg. C - Laboratory}

Bldg. $\mathrm{C}$ is a tri-level building with a basement partially above and partially below grade. For the most part, the temperature decayed relatively uniformly and as expected, with the thermal decay rate becoming faster moving from the 2nd floor through to the basement. In contrast, the results from other buildings with full basements, the additional insulation and thermal mass from the surrounding soil did not seem to inhibit the rate of decay, as was found in other buildings. This is due to the large fenestration area throughout the building and especially in the basement. Additionally there was a large open stairway column that ran from the 2nd floor to the basement allowing more cold air to infiltrate and sink to the bottom of the building.

Figure 5 shows the ambient temperatures from rooms located at different heights throughout the building. Bldg. $\mathrm{C}$ had a server room on the second floor that continued to operate throughout the test. While temperatures in other rooms were dropping, this room actually increased in temperature throughout the course of the test. It was not clear to what extent this had an effect on the other $2^{\text {nd }}$ floor rooms. In emergency scenarios internal loads suchs as information technology (IT) equipment, could be used to extend operation time for mission-critical staff, but this would be limited to the room where the equipment is housed.

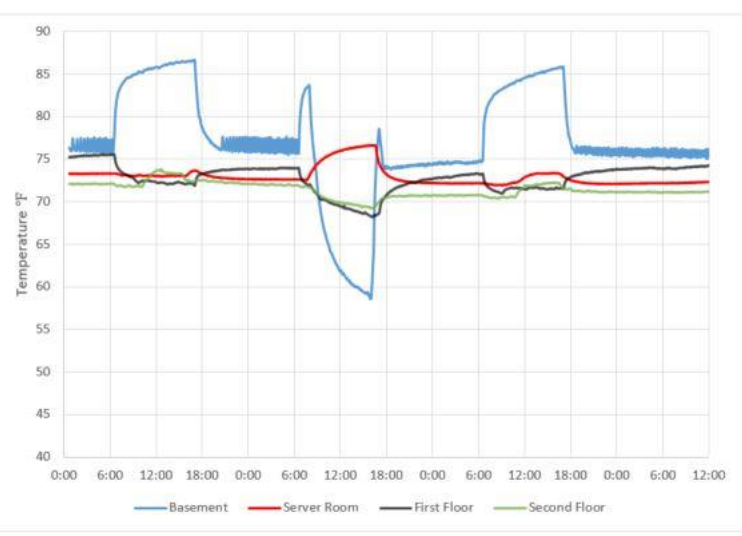

Figure 5. Bldg. C Ambient Temperatures throughout the Building.

\section{FGA Bldg. D - DPW Building}

The tests on FGA started at approximately 3:00 p.m. on 17-Jan and ran until 8:30 a.m. on 18-Jan. Bldg. D did not decay as uniformly as the buildings at FWA did. Room 104 (a garage bay) approached the critical temperature for the thermal decay test. Rooms 104 and 103 (wood shop) were connected by an open hallway and air flowed freely between the two rooms. Despite Room 103's pre-test temperatures being approximately $10^{\circ} \mathrm{F}\left(-12^{\circ} \mathrm{C}\right)$ lower than rooms 102 (office) and 104, its rate of decay was slower. Rooms 102 and 103 were on opposing corners of the building and air was not able to flow freely between the rooms. Rooms 102's rate of thermal decay was faster than that of Room 103 despite both having a similar insulation properties and Room 103 having a larger fenestration area.

Figure 6c compares the ambient temperatures for three different rooms in Bldg. D. Room 102 decayed significantly faster than Room 103 because it is directly in the path of the $60+\mathrm{mph}(97+\mathrm{kph})$ easterly winds experienced at Fort Greely during the night of the test. Room 102 was located on the south east corner of the building. This caused a positive pressure on the side of the building where Room 102 was located and a negative pressure on the side of the building where Room 103 was located. A pressure gradient was set up through the building causing warm air to exit the building on the west side and cold air to enter the building on the east side. As a result, air infiltration in rooms 102 and 104 was accelerated. In addition to the wind effect, Room 104 appeared to have less insulation than other rooms as this section of the building was built 
using different materials (metal sheeting) than the rest of the building.

Building materials with a larger thermal mass will release stored energy during a thermal energy disruption, inhibiting the rate of thermal decay. The data in Figure $6(a, b)$ may be used to compare two rooms with different building materials and different insulation values. Figure 6a shows that the ambient temperature (turquoise) closely follows just the temperature of the exterior wall (CMU/EIFS) surface temperature (red), but remains colder than the interior wall surface temperature (purple). This is because the exterior wall is resisting the change in outdoor vs. indoor temperature. Also, the interior wall is not directly exposed to the cold outside air and is able to retain more of its stored thermal energy causing a lag in temperature behind the exterior wall and ambient temperatures. This is important for building envelope design because while interior walls may not need to be built from heavier materials to maintain structural integrity, it may be beneficial for thermal energy resilience.

Figure $6 \mathrm{~b}$ shows that the ambient temperature deviates significantly from the surface temperatures for areas in which building materials have less thermal mass and lower insulation values (metal sheeting). This causes the ambient temperature to lag the surface temperature, as the metal sheeting is less resistant to changes in temperature. This ultimately leads to a faster rate of thermal decay and a shorter maximum time to repair.

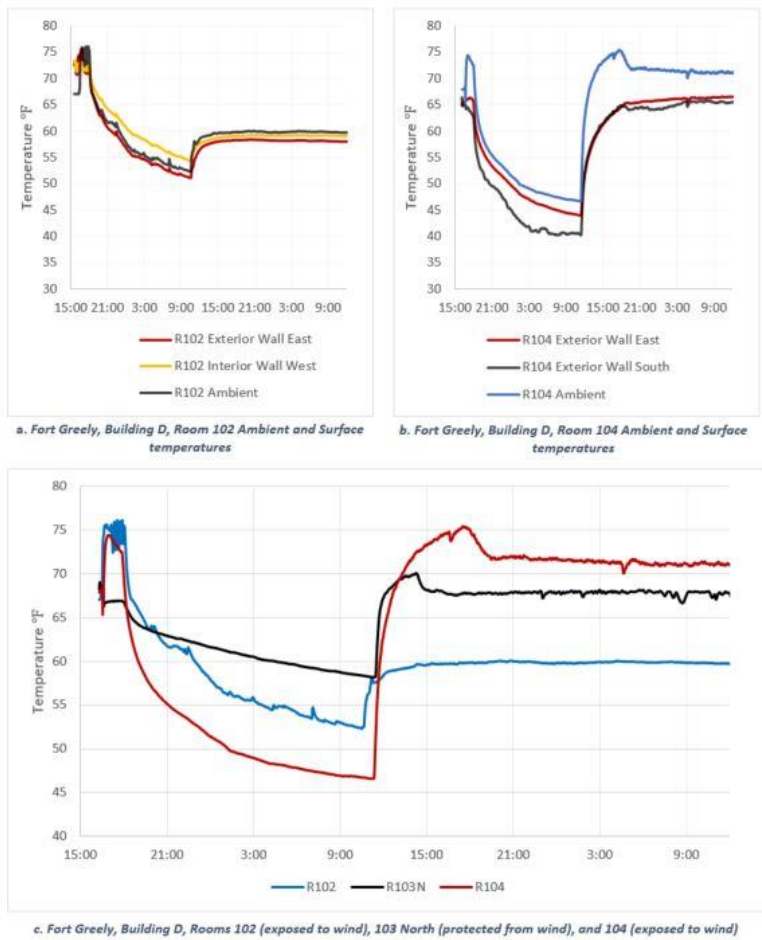

Figure 6. Test Results from FGA BIdg. D.

\section{FGA Bldg. E - MWR Building}

Bldg. E is separated into three sections isolated from one another. From east to west the main rooms in each of these sections are Room 125, 100, and 108 . Underneath Section 100 is a fully below grade basement, which is composed of two rooms (Room 001 and 002). Room 001 is the mechanical room and entrance for the steam pipes. The two rooms were separated by a wall with an open doorway. Room 002 was located near the staircase to the basement, which allowed for cold air to sink to the basement. Both rooms did not reach the critical threshold, despite being in the basement. Because to the basement walls are below grade and therefore not directly in contact with the outdoor air, the thermal mass of the CMU's and soil insulate the basement.

Over the course of the 17-hour test, Section 100 had the longest projected operation time. Section 100 is shielded on both east and west sides by sections 125 and 108 , respectively, while thermal energy also rises from the basement. The thermally saturated foundation and surrounding soil acted as a thermal battery, dissipating heat over the course of the test. Sections 108 and 125 are on opposing corners of the three-part building with room 110 being a room within section 108 and section 100 being located in the center. Section 125 had the most dramatic thermal decay curve and was located on the east side, directly in the path of the wind. Section 125 also had the largest fenestration area with large windows on the north and south side. Wind was a significant contributor to the thermal decay rates in FGA. The effects of wind can be seen in Figure 7c, which shows the difference in surface temperatures between the southeast (R125) and northwest (R110) corners of Bldg. E. At the start of the test, the southeast corner was approximately $5^{\circ} \mathrm{F}\left(-15^{\circ} \mathrm{C}\right)$ warmer than the northwest. 

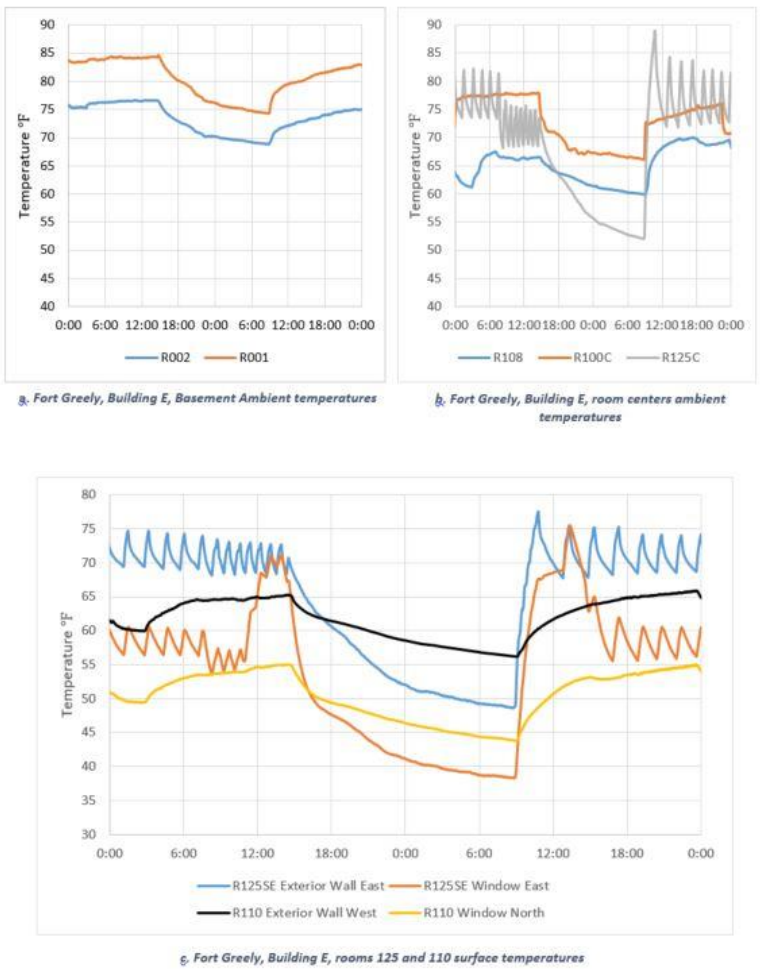

Figure 7. Test Results from FGA Bldg. E.

\section{SUMMARY AND CONCLUSION}

The thermal decay tests described in this paper were conducted on five buildings at two different locations in Alaska. The tests were designed to simulate a thermal energy disruption and to measure interior and exterior temperatures as well as relative humidity during the simulated event. The tests were halted when interior air temperatures approached $45^{\circ} \mathrm{F}\left(7^{\circ} \mathrm{C}\right)$ to ensure that no significant damage would be done to the buildings.

The following preliminary conclusions confirm that the airtightness, thermal mass, insulation properties, and internal loads of buildings affect the maximum time to repair thermal energy systems during a thermal energy disruption. As one might expect, the rate of thermal decay is not uniform throughout the building, depending on the environmental conditions. It was found that wind and solar position can accelerate or impede the rate of thermal decay within a building depending on building orientation and fenestration location. If possible, for fenestrations not exposed to direct sunlight, it is recommended to place an insulated barrier over windows and along door thresholds. Certain rooms were seen to have design issues, air leakage rates that may vary throughout the building, and certain rooms that are more vulnerable to a thermal energy disruption. This needs to be considered for predicting the maximum time to repair thermal energy systems, as it is necessary to factor in a tolerance for this estimate.

Wind was found to accentuate the rate of thermal decay in specific areas of buildings sustaining high speed winds. Wind creates a positive pressure on the upstream side of the building and a negative pressure on the downstream side, setting up a pressure gradient throughout the building. This causes warm air to escape out of the downstream side of the building allowing for cold air to infiltrate the building on the upstream side. This generally only affected rooms that were exposed to wind, but is still an important factor to consider for new construction and the placement of mission-critical staff and equipment as rooms downstream of the wind have an extended operation time compared to rooms upstream of the wind. Additionally, it is recommended that particularly vulnerable rooms (e.g. mechanical rooms with exposed water pipes) be placed underground or in locations that are not directly exposed to wind.

Internal loads were shown to extend operation time, but is dependent on the scale of the load and is limited to the room the load is being housed in. The temperature in a room housing a server rack increased in temperature over the course of the test, despite the other rooms losing thermal energy. According to Zhivov et al. (2021a) many mission-critical facilities or dedicated spaces within these facilities house computer systems. This is significant because, strategic placement of these systmes could add an additional layer of thermal resilience to these dedicated spaces within these facilities.

Insulation ratings appear to significantly increase operation time during a thermal energy disruption. Buildings with higher insulation ratings performed better in colder temperatures. After 8 hours of testing in $-40^{\circ} \mathrm{F}\left(-40^{\circ} \mathrm{C}\right)$, Bldg. A in FWA showed little to no sign of thermal decay. In contrast, after 8 hours of testing, buildings with lower insulation ratings at FGA showed a significant amount of thermal decay. This was even found within Bldg. D which had a garage bay, built with a lower insulation rating, which showed a faster rate of decay than other parts of the building.

Building design was found to contribute significantly to a buildings thermal energy systems resilience. Bldg. B appeared to outperform all other buildings in this study, which was likely due to the radiant slab glycol heating system. Bldg. B was unique among the tested buildings in that it was the only building with a radiant slab glycol heating system. This system acted as a thermal battery, which allowed residual heat to be dissapated throughout the building thoughout the course of the test extending the operation time. This was further improved by the overheated mechanical room, where the glycol heating system originates. Additionally, Bldg. B had a large fenestration area, which allowed solar radiation to heat certain parts of the building, extending operation time even further in specific areas of the building.

During the course of the test, the ambient temperature fell lower than the internal surface temperatures, This lag in surface temperature indicates that the thermal mass (construction materials) of a building makes a significant contribution to the overall thermal resilience of a building. As the ambient temperature falls due to air penetration and conduction via the external walls, the internal walls radiated stored heat, inhibiting the rate of temperature decay. While 
using CMU's or stone for internal and external building features, may be less feasible or result in higher costs, it does provide an additional layer of thermal resilience to a building. 
This research was partially supported by the DoD Environmental Security Technology Certification Program, the Office of the Deputy Assistant Secretary of the Army, US Army Program 633734T1500, Military Engineering Technology Demonstration, and the International Energy Agency Energy in Buildings and Communities Program Annex 73.

We express our gratitude for the extensive support from the Fort Greely DPW Staff: Ms. Mathea Meurer, Mr. Clifford "Shawn" Baker, Mr. Todd Hayden, and Mr. Clay Trabel and Fort Wainwright DPW Staff: Mr. Bill Chedister.

\section{References}

ASHRAE. 2015. Cold-Climate Buildings Design Guide. ASHRAE1791 Tullie Circle NE, Atlanta, GA.

Design Objectives. Whole Building Design Guide (WBDG), National Institute of Building Sciences, 2020, wbdg.org/.

DoD 2020. DoD Memorandum. Metrics and Standards for Energy Resilience at Military Installations. Metrics and Standards for Assessment of Energy Resilience, Supporting Policy and Guidance and Associated Reporting Requirements. 15 February 2020.

IMCOM. 2010. Energy and Water Conservation Design Requirements for Sustainment, Restoration and Modernization (SRM) Projects and MILCON Construction. USACE ERDC.

Kesik, T., L. O’Brien, A. Ozkan. 2019. Thermal Resilience Design Guide. 2019. Sponsored by ROCKWOOL North America.
Koval, D. O., R. G. Arno, B. Roczen, T. Coyle, P. O’Donnell, W. E. Brumsickle, R. J. Schuerger, W. F. Braun, A. A. Chowdhury, P. Gross, P. S. Hale, C. R. Heising, and K. O'Donnell, IEEE Recommended Practice for the Design of Reliable Industrial and Commercial Power Systems. New York, NY: Institute of Electrical and Electronics Engineers, 2007.

Leffel, Emmett. 2021. Building Enclosure Testing on Alaska Military Base Projects. ASHRAE Transactions. Vol. 127 Part 1.

Presidential Policy Directive 21 (PPD-21). 2013. Critical Infrastructure Security Resilience.

TM 5-698-1. Reliability/availability of electrical and mechanical systems for command, control, communications, computer, intelligence, surveillance and reconnaissance (C4ISR) facilities. Department of the Army, HQ. 19 January 2007.

Zhivov, Alexander, David Bailey, and Dale Herron. 2012. U.S. Army Corps of Engineers Air Leakage Test Protocol for Building Envelopes. Version 3.

Zhivov, Alexander, William Rose, Raymond Patenaude, and William Warren. 2021a. Requirements for Building Thermal Conditions under Normal and Emergency Operations in Extreme Climates. ASHRAE Transactions. Vol. 127, Part 1.

Zhivov, Alexander, Andrew Stringer, Michael Fox, John Benefiel, Patrick Daniels, and Todd Tarver. 2021b. Defining, Measuring and Assigning Resilience Requirements to Electric and Thermal Energy Systems. ASHRAE Transactions. Vol. 127, Part 1 